Int. J. Dev. Biol. 48: 671-674 (2004)

doi: $10.1387 / \mathrm{ijdb} .041853 \mathrm{sw}$

Short Communication

\title{
Distinct neural precursors in the developing human spinal cord
}

\author{
SALLY WALDER and PATRIZIA FERRETTI* \\ Developmental Biology Unit, Institute of Child Health, University College London, London, UK.
}

\begin{abstract}
Both embryonic and adult central nervous system have been shown to contain multipotent neural stem cells, but it is not yet clear whether they consist of a single or distinct populations of neural precursors. Since embryonic human neural precursors, particularly in the spinal cord, have not been extensively characterized, we have studied their behaviour at different days of gestation and in different culture conditions. Depending on dissociation and culture conditions, neurospheres which contain nestin- and vimentin-positive or only vimentin-positive neural precursors can be isolated. Whereas the former can be isolated only at early developmental stages, the latter appear to be present at all the stages examined, between 45 and 89 days of gestation. Furthermore, comparison of the effect of FGF, EGF and the two factors in combination on colony formation shows an additive effect of the two growth factors, indicating the existence of more than one type of neural precursor. Overall our results suggest that the human spinal cord contains distinct and dynamic populations of neural precursors which are developmentally regulated.
\end{abstract}

KEY WORDS: development, embryo, human, spinal cord, neural stem cell

The central nervous system (CNS) forms from the neural tube. This is initially a simple epithelium from which through finely orchestrated events including proliferation, differentiation and morphogenesis the CNS emerges in all its complexity. The idea that all neural precursors become progressively more restricted and disappear with age has been challenged by much evidence for the presence of multipotent neural precursors throughout development and in adulthood. Many studies have recently focused on the identity and behaviour of these cells both to better understand the mechanisms underlying neural development and in the hope of using them as therapeutic agents in diseased or injured CNS (Ferretti, 2004, Gage, 2000, Johansson, 2003). Both FGF2 and EGF have been shown to play a role in maintaining neural progenitor cell cycling in vitro, though they play several other roles in neural development, serving different functions at different stages (Cameron et al., 1998, Dono, 2003, Gritti et al., 1996, Shihabuddin et al., 1997, Vescovi et al., 1993, Wong and Guillaud, 2004). There are some discrepancies in the literature regarding the actions of these two growth factors on stem cell growth and on whether the brain contains a single multipotent precursor or multiple populations (Gritti et al., 1999, Tropepe et al., 1999). Characterization of human embryonic neural stem cells is still limited, particularly in the case of the developing spinal cord (Jain et al., 2003, Quinn et al.,
1999), as most studies, both in animal and humans, have tended to focus on brain stem cells. Therefore, we have examined the behaviour of human embryonic spinal cord stem cells grown under different conditions and assessed the effects of FGF2 and EGF in cultures derived from human spinal cord at different developmental stages. Spinal cord cells from embryos at 40, 52, 54 and 56 days of gestation $(\mathrm{dg})$ plated in the presence of serum onto fibronectin and then cultured in serum-free medium initially attached to the dish. However, within 2 to 3 weeks in culture, these small adherent cells detached forming floating spheres, neurospheres, that continued to grow in suspension. A small number of the attached cells appeared to differentiate but quickly died and disappeared from the culture. The population of small cells that gave rise to the spheres was still present after a month in culture although the rate of division and therefore sphere production, was greatly decreased. In contrast, most cells from older spinal cords, 80 and $84 \mathrm{dg}$, had a flattened morphology and only occasionally small, floating spheres were found in these cultures after about 2 weeks. Therefore

\footnotetext{
Abbreviations used in this paper: CNS, central nervous system; dg, days of gestation; EGF, epidermal growth factor; FGF, fibroblast growth factor; GFAP, glial fibrillary acidic protein.
}

\footnotetext{
*Address correspondence to: Dr. Patrizia Ferretti. Developmental Biology Unit, Institute of Child Health, 30 Guilford Street, London WC1N 1EH, UK. Fax: +44-20-7831-4366. e-mail: ferretti@ich.ucl.ac.uk
} 
cultures from young embryonic spinal cord give rise to an adherent population of small, fast-growing cells that form neurospheres.

In order to analyze the cell content of these neurospheres, we studied expression of neural stem cell and differentiated cell markers in sections of 2 week old neurospheres derived from a $56 \mathrm{dg}$ spinal cord. Several cells expressed the progenitor cell antigens vimentin and nestin and expression of the latter appeared higher toward the centre of the sphere than at the periphery (Fig. $1 \mathrm{~A}, \mathrm{~B}$ ). In addition, expression of the astrocyte

marker GFAP and of the neuronal marker 3A10 was observed (Fig. 1 C,D). Neuronal staining appeared to be extremely low in the centre of the sphere. A small number of cells positive for $\mathrm{O}$, an oligodendrocyte marker, were also observed and they were restricted to the periphery of the neurosphere (Fig. 1E). Overall it appears that the neurosphere core consists mainly of neural precursors whereas more peripherally both neural precursors and differentiated cells are present.

To assess the differentiation potential of neurospheres from embryonic spinal cords, they were induced
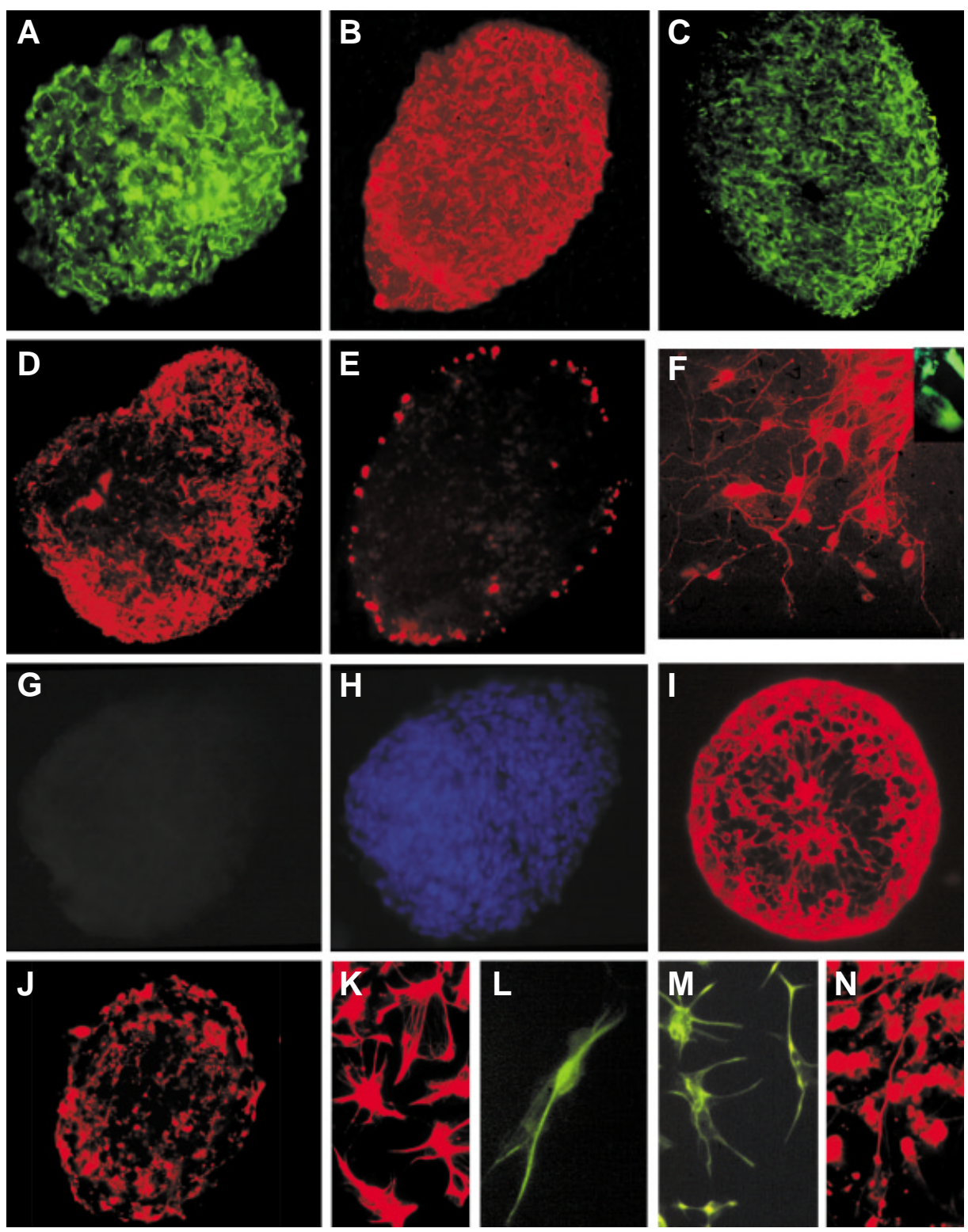

Fig. 1. Staining of floating neurospheres and differentiating cells from human embryonic spinal cord cultures. (A-E) Immunostaining of sections of a neurosphere derived from a $56 \mathrm{dg}$ human spinal cord with initial exposure to fetal calf serum and maintained in culture for 14 days. (A) Nestin; (B) vimentin; (C) GFAP; (D) 3A10; (E) O4. (F) Cells from neurospheres induced to differentiate stained for RT97 (neurofilaments, red) and GFAP (insert, green). (G-J) Wholemount immunostaining of neurospheres derived from $45 \mathrm{dg}(\mathrm{G}-\mathrm{I})$ and $72 \mathrm{dg}$ spinal cords without any exposure to serum. (G) Nestin; (H) Hoechst nuclear staining; (I-J) vimentin. (K-N) Cells from neurospheres induced to differentiate stained for (K) vimentin; (L) nestin; (M) GFAP and (N) RT97. to differentiate by plating on gelatinecoated coverslips in serum-containing medium without FGF2. The neurospheres readily adhered to the gelatine, flattened and spread to yield large numbers of migrating cells. Immunofluorescent staining with antibodies against GFAP, neurofilament protein, nestin and $\mathrm{O} 4$ revealed the presence of astrocytes, neurons (Fig. 1F) and some nestin-expressing cells, but no oligodendrocytes were detected (not shown). The different cells types observed following attachment are most likely derived from multipotent precursors, as when we grew spinal cord cells as a monolayer we found that neurons were present only early after plating and survived only a few days in culture (not shown). A significant difference in protein profile was observed in neurospheres obtained from mechanically dissociated cultures not exposed to serum and grown in suspension. These neurospheres did not express nestin (Fig. $1 \mathrm{G}, \mathrm{H}$ ) nor any differentiation marker (not shown), but were vimentin positive at 3,7 and 14 days after plating (Fig. $1 \mathrm{I}, \mathrm{J})$. This was independent from the stage of development, as the same results were obtained with spinal cords from 45, 72 and $89 \mathrm{dg}$. When transferred into medium containing serum to induce differentiation, the presence of some nestin-positive cells, in addition to vimentin, GFAP and neurofilament proteins could be detected (Fig. $1 \mathrm{M}, \mathrm{N}$ ), indicating that the cells present in these neurospheres are multipotent. Overall our results suggest the existence of different stem cell populations that can be selected by using different isolation conditions. The existence of a nestin-negative cell able to give rise to neurons and glia was reported also in neurosphere cultures from adult mouse brain (Kukekov et al., 1997). This cell population did not initially express the progenitor cell marker nestin, though its expression was detected as the cells matured and it was suggested that it represented an ontogenetically ear- 


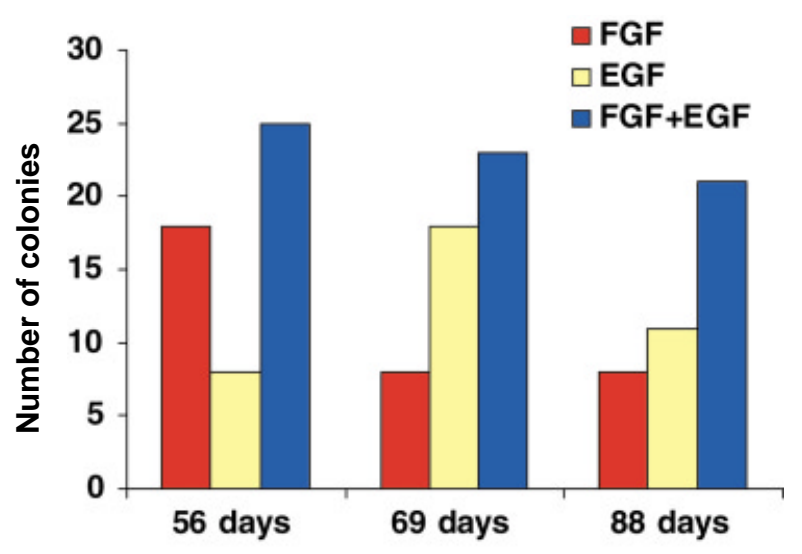

Fig. 2. Effect of FGF2 and EGF alone or in combination on the formation of colonies from human embryonic spinal cord cells. Note that the effect of EGF and FGF in combination is always higher than the effect of the individual growth factors.

lier type of cell than those described by other groups, which may have been overlooked in previous studies.

We observed that when spinal cord cells that had been isolated enzymatically and never exposed to serum were grown in wells containing a coverslip, individual cells would nestle beneath it and grow as non-adhering colonies, as shown upon coverslip removal. This allowed them to be easily counted and to be maintained as discrete entities, unlike in floating condition where fusion of aggregates was noticed to occur. We used this system to compare the effect of FGF and EGF treatment alone and in combination on spinal cord cultures set up from embryos at 56, 69, 88 and 89 days of gestation. An equal number of cells from each spinal cord cell suspension was divided between three wells and grown in serum-free medium containing FGF, or EGF or FGF+EGF. Rounded colonies of progenitor cells formed in all of the media used and survived for at least 30 days. At all the developmental stages studied the effect of the two growth factors appears to be additive, suggesting that they support growth of different subsets of precursors (Fig. 2). The relative number of colonies present in FGF2-supplemented and EGF-supplemented media, however, seemed to vary with spinal cord age. In younger spinal cord cultures, FGF2 appeared to induce formation of a higher number of colonies than EGF, whereas in older cultures EGF seemed to be more effective. The existence of separate neural stem cell lineages, a early one responsive to FGF and a later emerging one responsive to EGF, has been reported in the embryonic mouse telencephalon (Tropepe et al., 1999), though in the adult, existence of a single multipotent stem cell responding to these factors has been proposed (Gritti et al., 1999). Our results suggest that multiple cell populations responding primarily to FGF or EGF are present across species, at least during development, and in different regions of the central nervous system. Nonetheless, it is also important to point out that neurospheres from different brain regions behave differently and we have observed that, unlike in the case of brain-derived neurospheres, it was very difficult to maintain human spinal cord derived neurospheres for more than 4 weeks in culture and that their neuronal differentiation tended to be less vigorous than in brain-derived cultures (not shown). This is consistent with other studies on human spinal cord cells where growth of neural precursors was found to be quite limited and their differentiation potential was seen to decrease with age (Jain etal., 2003, Quinn et al., 1999).

In conclusion, our work suggests that the developing human spinal cord contains different populations of multipotent cells, as indicated by protein expression profile in neurospheres isolated and grown under different conditions and by the ability to form colonies in the presence of FGF and EGF. It also suggests that different precursor populations are regulated with development in a different fashion, as the nestin-/vimentin+ precursor could be isolated at all of the gestational ages tested, whereas neurospheres containing nestin+/vimentin+ precursors were more readily generated at early stages of development.

\section{Experimental Procedures}

Human embryonic brain and spinal cord between 40 and 89 days of gestation (dg) were obtained under ethical approval from the MRC/ Wellcome Trust Human Developmental Biology Resource. Given the nature of the collection and ethical issue involved it was difficult to obtain multiple embryos at identical stages of development.

Spinal cord cells were grown in serum-free medium DMEM containing transferrin $(50 \mu \mathrm{g} / \mathrm{ml})$, insulin $(5 \mu \mathrm{g} / \mathrm{ml})$ putrescine $(100 \mu \mathrm{M})$, progesterone $(20 \mathrm{nM})$, sodium selenite ( $30 \mathrm{nM})$, penicillin-streptomycin (100 units $/ \mathrm{ml})$ and FGF2 (fibroblast growth factor; $10 \mathrm{ng} / \mathrm{ml}$ bovine) unless otherwise indicated. Differentiation was induced by plating them onto gelatine in DMEM containing $10 \%$ foetal calf serum (FCS). Cells were fed every three days.

Spinal cords were dissected out of human embryos at different days of gestation (dg) in L15 medium and minced. The tissue was then washed three times with $\mathrm{Ca}^{++}$and $\mathrm{Mg}^{++}$free phosphate buffer saline (PBS), incubated for 20 minutes at $37^{\circ} \mathrm{C}$ in a $0.5 \%$ trypsin and triturated mechanically in $\mathrm{Ca}^{++}$and $\mathrm{Mg}^{++}$free PBS Hanks BSS containing $250 \mu \mathrm{g} / \mathrm{ml}$ of DNase 1. Cell suspensions were centrifuged and pellets resuspended either in medium containing $10 \%$ FCS or in serum-free medium and plated onto fibronectin $(1 \mathrm{ng} / \mathrm{ml})$ coated dishes or onto uncoated dishes, respectively. Cell resuspended in the presence of FCS were maintained in this medium for the initial 2 days in culture and then grown in the serum free medium. In some experiments EGF (epidermal growth factor; $10 \mathrm{ng} / \mathrm{ml}$ human recombinant) instead of FGF was added to the medium, or the two factors were used in combination. Cells from one spinal cord were plated in each well of a 24 well plate. In another set of experiments the enzymatic digestion was omitted and a single cell suspension was prepared by using only mechanical dissociation; these cells were always grown in serum-free medium. In some experiments coverslips were inserted in the well prior to plating for colony counting.

\section{Immunocytochemistry}

Floating neurospheres from cultures initially exposed to serum were collected, OCT embedded and cryostat sectioned prior to immunostaining. Floating neurospheres grown under the other conditions tended to be smaller and more difficult to embed for cryostat sectioning, therefore drops of neurosphere containing medium were allowed to air dry on polylysinecoated slides and neurosphere stained essentially as previously described (O'Neill et al., 2004). The following primary antibodies were used: rabbit anti-nestin (1:50; (Tohyama et al., 1992); mouse anti-vimentin (PA1, 1:3; Boehringer Mannheim); mouse anti-neurofilament and mouse antineurofilament associated protein (RT-97, 1:100 and 3A10, 1:100; Hybridoma Bank, University of lowa); mouse anti-O4 (MAB345, 1:40; Chemicon); rabbit anti-GFAP (1:100; DAKO, UK).

\section{Acknowledgements}

We wish to thank Ron McKay for providing the anti-nestin antibody. This work was supported by the Child Research Appeal Trust and The Wellcome Trust. 


\section{References}

CAMERON, H.A., HAZEL, T.G. and MCKAY, R.D. (1998). Regulation of neurogenesis by growth factors and neurotransmitters. J Neurobio/36: 287-306.

DONO, R. (2003). Fibroblast growth factors as regulators of central nervous system development and function. Am J Physiol Regul Integr Comp Physio/284: R86781.

FERRETTI, P. (2004). Neural stem cell plasticity: Recruitment of endogenous populations for regeneration. Curr. Neurovasc. Res. 1: 215-229.

GAGE, F.H. (2000). Mammalian neural stem cells. Science 287: 1433-8.

GRITTI, A., FROLICHSTHAL-SCHOELLER, P., GALLI, R., PARATI, E.A., COVA, L., PAGANO, S.F., BJORNSON, C.R. and VESCOVI, A.L. (1999). Epidermal and fibroblast growth factors behave as mitogenic regulators for a single multipotent stem cell-like population from the subventricular region of the adult mouse forebrain. JNeurosci19: 3287-97.

GRITTI, A., PARATI, E.A., COVA, L., FROLICHSTHAL, P., GALLI, R., WANKE, E., FARAVELLI, L., MORASSUTTI, D.J., ROISEN, F., NICKEL, D.D. et al. (1996). Multipotential stem cells from the adult mouse brain proliferate and self-renew in response to basic fibroblast growth factor. JNeurosci 16: 1091-100.

JAIN, M., ARMSTRONG, R.J., TYERS, P., BARKER, R.A. and ROSSER, A.E. (2003). GABAergic immunoreactivity is predominant in neurons derived from expanded human neural precursor cells in vitro. Exp Neuro/182: 113-23.

JOHANSSON, C.B. (2003). Mechanism of stem cells in the central nervous system. J Cell Physio/196: 409-18.

KUKEKOV, V.G., LAYWELL, E.D., THOMAS, L.B. and STEINDLER, D.A. (1997). A nestin-negative precursor cell from the adult mouse brain gives rise to neurons and glia. Glia 21: 399-407.
O'NEILL, P., WHALLEY, K. and FERRETTI, P. (2004). Nogo and its receptor in human and chick: Implications for development and regeneration. Dev. Dyn. 231: 109121

QUINN, S.M., WALTERS, W.M., VESCOVI, A.L. and WHITTEMORE, S.R. (1999) Lineage restriction of neuroepithelial precursor cells from fetal human spinal cord. JNeurosci Res 57: 590-602.

SHIHABUDDIN, L.S., RAY, J. and GAGE, F.H. (1997). Fgf-2 is sufficient to isolate progenitors found in the adult mammalian spinal cord. Experimental Neurology 148: 577-586.

TOHYAMA, T., LEE, V.M., RORKE, L.B., MARVIN, M., MCKAY, R.D. and TROJANOWSKI, J.Q. (1992). Nestin expression in embryonic human neuroepithelium and in human neuroepithelial tumor cells. Lab Invest 66: 303-13.

TROPEPE, V., SIBILIA, M., CIRUNA, B.G., ROSSANT, J., WAGNER, E.F. and VAN DER KOOY, D. (1999). Distinct neural stem cells proliferate in response to EGF and FGF in the developing mouse telencephalon. Dev Bio/208: 166-88.

VESCOVI, A.L., REYNOLDS, B.A., FRASER, D.D. and WEISS, S. (1993). bFGF regulates the proliferative fate of unipotent (neuronal) and bipotent (neuronal/ astroglial) EGF-generated CNS progenitor cells. Neuron 11: 951-66.

WONG, R.W. and GUILLAUD, L. (2004). The role of epidermal growth factor and its receptors in mammalian CNS. Cytokine Growth Factor Rev15: 147-56.

Received: June 2004

Reviewed by Referees: August 2004

Modified by Authors and Accepted for Publication: August 2004 